\title{
AS POLÍTICAS PÚBLICAS E O DIREITO À EDUCAÇÃO: PROGRAMA NACIONAL DE ACESSO AO ENSINO TÉCNICO E EMPREGO VERSUS PLANO NACIONAL DE EDUCAÇÃO*
}

\author{
Marcelo Lima ${ }^{1,2,3}$ \\ Zilka Sulamita Teixeira de Aguilar Pacheco ${ }^{3,4}$
}

\begin{abstract}
RESUMO: Com base em análises bibliográfica e documental, buscamos tencionar questóes que perpassam o Plano Nacional de Educação (PNE) e o Programa Nacional de Acesso ao Ensino Técnico e Emprego (PRONATEC), relacionando sua origem, sua concepção e seus objetivos. O PNE, mesmo não consolidado, revela-se como uma política de Estado, possibilitando a estruturação do direito à educação ao propor a superação das desigualdades educacionais, a promoção da qualidade educacional e o fortalecimento do financiamento da educação. Já o PRONATEC emerge sem a participação mais ampla da sociedade e é responsável por elevar o número de matrículas na educação profissional, indicando, entretanto, caráter de política de governo de viés privatista, priorizando, via bolsa formação, cursos predominantemente de curta duração.
\end{abstract}

Palavras-chave: Direito à educação. Política pública. Plano Nacional de Educação. Programa Nacional de Acesso ao Ensino Técnico e Emprego.

\section{THE PUBLIC POLICIES AND THE RIGHT TO EDUCATION: National Program for Access to Technical Education AND EMPLOYMENT VERSUS NATIONAL EDUCATION Plan}

ABSTRACT: Based on bibliographical and documentary analysis, we seek intend issues that pervade the National Education Plan (PNE) and the National Program for Access to Technical Education and Employment (PRONATEC) relating its origin, design and goals. The PNE, even unconsolidated, reveals itself as a state policy,

\footnotetext{
*Artigo é parte integrante de pesquisa do projeto de pesquisa no 6068/2015 denominado "A Política de Educação Básica e Profissional no Espírito Santo: fundamentos, práticas docentes, normativas, currículos e metodologias de ensino e de gestão da formação profissional" apoiado e financiado pelo PIIC (programa institucional de iniciação científica) da UFES e localizado no LAGEBES (Laboratório de gestão da educação básica do Espírito Santo).

${ }^{1}$ Universidade Federal do Espírito Santo (UFES) - Vitória (ES), Brasil. E-mail: marcelo.lima@ufes.br; zilkas.teixeira@gmail.com

${ }^{2}$ Universidade Federal Fluminense (UFF) - Niterói (RJ), Brasil.

${ }^{3}$ Programa de Pós-Graduação em Educação (PPGE),UFES - Vitória (ES), Brasil.

${ }^{4}$ Instituto Federal de Educação, Ciência e Tecnologia do Espírito Santo (IFES) - Vitória (ES), Brasil. DOI: 10.1590/ES0101-73302017167752
} 
allowing the structuring of the right to education by proposing to overcome educational inequalities, promoting educational quality and strengthening education funding. On the other hand, PRONATEC emerges without the participation of the wider society and is responsible for raising the number of enrollments in vocational education, revealing, however, a private character bias of government policy, prioritizing, via exchange training, predominantly short courses.

Keywords: Right to education. Public policy. National Education Plan. National Program of Access to Education Technical and Employment.

\section{POLITIQUES PUBLIQUES ET DROIT À L'ÉDUCATION: Programme NATIONAL POUR L'ACCÈs À L'ENSEIGNEMENT TECHNIQUE ET À L'EMPloI VERSUS Plan NATIONAL D'ÉduCATION}

RÉSUMÉ: Basé sur une analyse bibliographique et documentaire, nous cherchons à mettre en relation des questions présentes dans le Plan National d'Éducation (PNE) et le Programme National pour l'Accès à l'Enseignement Technique et de l'Emploi (Pronatec) en ce qui concerne leur origine, leur conception et leurs objectifs. Le PNE, même si non consolidé, se révèle comme une politique d'État et permet la structuration du droit à l'éducation quand il propose de surmonter les inégalités éducatives, la promotion de la qualité de l'éducation et de renforcer le financement de l'éducation. Par contre, le Pronatec émèrge sans la participation plus ample de la société et est le responsable de l'augmentation du nombre d'inscriptions dans l'enseignement professionnel ce qui indique toutefois le caractère de politique gouvernementale de biais privatiste qui priorise, par l'intermédiaire d'une bourse de formation, des cours principalement de courte duration.

Mots-clés: Droit à l'éducation. Politique publique. Plan National D'education. Programme National Pour L'accès à L'enseignement Technique et à L'emploi.

\section{Introdução}

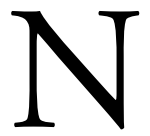

este trabalho, buscamos tencionar algumas questóes que atravessam o Plano Nacional de Educação (PNE) 2014-2024, marco capital das políticas públicas educativas brasileiras, e o Programa Nacional de Acesso ao Ensino Técnico e Emprego (PRONATEC), principal política pública nacional de Educação Profissional e Tecnológica (EPT) da contemporaneidade. Com orientação marxiana, este estudo, bibliográfico-documental, tem viés qualitativo. Foram utilizados como referência trabalhos de Bomeny (2003), Gentili (2009), Lima (2011), Lima (2014), Ribeiro (2006), Saviani (2007) e Rua (s.d.), e como fonte de dados, estudos e relatórios produzidos pelo Instituto Nacional de 
Estudos e Pesquisas Educacionais Anísio Teixeira (INEP), pela Secretaria de Articulação com os Sistemas de Ensino (SESA) e pela Secretaria de Educação Profissional e Tecnológica (SETEC), todos ligados ao Ministério da Educação (MEC), bem como o texto para discussão do Instituto de Pesquisa Econômica Aplicada (IPEA) e outras publicaçóes disponibilizadas na página do MEC na rede mundial de computadores e as leis de instituição do PRONATEC e de aprovação do PNE.

O PNE, aprovado pela Lei no 13.005 , de 25 de junho de 2014, representa um avanço no que tange à consolidação de um sistema nacional de educação e à possibilidade de concretização do direito à educação no Brasil. O plano, a ser monitorado bianualmente, ainda náo publicou seu primeiro relatório, referente ao período compreendido entre 2014 e 2016. Então, as análises e consideraçóes feitas neste texto dizem respeito ao que o plano estabelece, e não ao que já foi efetivamente realizado.

O PRONATEC, aprovado pela Lei $n^{\circ} 12.513$, de 26 de outubro de 2011, incorpora várias ações anteriores à sua criação e institui o Bolsa Formação, iniciativa que visa à qualificação e à habilitação de trabalhadores e estudantes brasileiros, constituindo foco de disputa pelos recursos públicos. Esse programa é responsável por mais de 8,1 milhóes de matrículas em cursos de Educação Profissional Técnica de Nível Médio (EPTNM) e de Formação Inicial e Continuada (FIC) de 2011 a 2014. Sua abrangência ultrapassou o número de 4.300 municípios brasileiros, envolvendo 15 ministérios do governo Dilma Rousseff e as redes pública e privada, e o programa movimentou mais de $\mathrm{R} \$ 14$ bilhóes no mesmo período, conforme informaçóes disponibilizadas no sítio do MEC.

Buscando analisar as origens, as concepçóes e os resultados tanto do PNE quanto do PRONATEC, com vistas a estabelecer relaçóes entre eles, este trabalho foi estruturado em duas seçōes, a saber:

1. Seção 1: "Educação profissional e tecnológica e a exclusão educacional: abordagens políticas e conceitos", em que se pretende discutir questôes que tangenciam as raízes históricas da EPT e a exclusão educacional;

2. Seção 2: "O PNE e o PRONATEC: as políticas públicas e o direito à educação", em que se espera tencionar algumas questóes acerca da origem, das concepçóes e dos resultados tanto do plano quanto do programa, relacionados às aproximaçóes e aos distanciamentos da educação básica e da educação profissional.

\section{Educação profissional e tecnológica e a exclusão educacional: abordagens políticas e conceitos}

A educação constitui um processo de aprender e de ensinar os saberes necessários para a vida em sociedade. Por isso, sua origem confunde-se com o surgimento do 
próprio homem, que, ao adaptar a natureza a si, acabou por transformá-la, trabalhando, aprendendo, ensinando, produzindo cultura e compondo sua existência.

Nessa perspectiva, o trabalho é o agir sobre a natureza, transformando-a em função das necessidades humanas. Consiste, portanto, na essência do homem, um feito humano, localizado no tempo e no espaço, resultado de processos históricos. Logo, o que o homem é coincide com sua produção - com o que produz e com o modo como produz.

Nas sociedades primitivas, a apropriação dessa produção era feita de maneira coletiva. Não havia divisão entre classes sociais, e a educação ocorria ao mesmo tempo em que se produzia a existência humana. Com a complexificação do trabalho humano, tornaram-se necessárias aprendizagens específicas, e, simultaneamente, iniciava-se um processo de divisão social do trabalho com base na propriedade privada do principal meio de produção: a terra. Nesse contexto, a escola apareceu para ensinar aos que tinham tempo livre e que não trabalhavam mais, pois tinha quem trabalhasse por/para eles. A escola, então, tem sua origem na divisão do trabalho manual e do trabalho intelectual (SAVIANI, 2007, p. 152-156).

Nas sociedades modernas, o eixo de produção deslocou-sedo campo para a cidade, da agricultura para a indústria. As forças produtivas desenvolveramse e passaram a empregar a ciência, que se materializou com novos meios e formas de produção. Para a inserção nessa nova sociedade, era necessário adquirir aprendizagens diversas e, nessa perspectiva, a educação escolar foi ampliada, com vistas a atender às demandas de formação do modelo capitalista de produção.

Nas sociedades capitalistas de países periféricos como o Brasil, a educação escolar não possibilita a todos os indivíduos o acesso a todos os níveis, formas e modalidades de ensino. Ela enseja também formas diferenciadas de socialização que oferecem trajetórias escolares diversas que, por sua vez, levam os indivíduos à inserção social subordinada ou não na sociedade. Nesse sentido, a função social da escola tem como um de seus elementos fundantes a contradição, que lhe é estrutural e que diz respeito ao seu papel de mediação dialética, sendo historicamente determinada na condição de reprodutora e/ou transformadora das relações sociais.

A história da educação brasileira é marcada pelo descaso das elites com a educação básica para todos e pela sua tradição privatista. Em 1870, o analfabetismo beirava os $80 \%$ da população em idade escolar. Apesar da abolição da escravatura, o contingente de ex-escravos não foi atendido em suas necessidades econômicas nem culturais, e o advento da República acentuou ainda mais as desigualdades ao responsabilizar estados e municípios pela educação básica. "A república dos bacharéis era também a república dos coronéis, mas estava muito distante de ser a república dos cidadãos” (BOMENY, 2003, p. 18-19).

No início do século XX, a maneira encontrada pelas elites para colocar o Brasil na civilização ocidental foi implantar uma sistemática política de imigração, em vez de 
promover a emancipação cultural e econômica da população composta, em sua maioria, de ex-escravos. Os objetivos eram "branquear" a sociedade e inserir pessoas letradas e em condiçóes de incorporar o trabalho moderno. Somente com a Primeira Guerra Mundial e o processo de imigraçáo ter sido dificultado é que o país se viu obrigado a olhar para seus próprios recursos humanos. A massa, sem cultura e abandonada, teria deser preparada às pressas para a atividade industrial urbana (BOMENY, 2003, p. 19-21).

Como a escolarização da população brasileira se mostrou inadequada para esse tipo de atividade produtiva, a solução brasileira foi a criação e o aprimoramento das escolas técnicas e do ensino industrial para os "meninos desvalidos", os "órfãos", os "abandonados" e os "desfavorecidos de fortuna”. Tal política era um plano assistencial aos "necessitados de misericórdia pública; um plano de regeneração pelo trabalho" e não um programa educacional. Assim, a educação profissional nasceu associada aos cidadãos de "segunda classe", vinculaçáo que se consolidou na cultura brasileira (BOMENY, 2003, p. 19-21).

No Brasil, a exclusão educacional foi tornando-se um impedimento ao desenvolvimento das forças produtivas no contexto do trabalho moderno cada vez mais complexo. Cada vez mais, a educação apresentava-se como tema de grande relevância que envolvia questōes sociais, econômicas, políticas e tecnológicas fundamentais para a inserção social dos indivíduos, transformando-se em objeto de políticas de combate à exclusão.

Ribeiro (2006), ao problematizar as questóes que permeiam a exclusão educacional, propóe que o conceito de exclusão social seja analisado em profundidade, para "além da superfície". Para a autora, devem-se aprofundar as razóes pelas quais uns estão incluídos e outros excluídos, em que tempos e espaços ocorrem os processos excludentes e includentes, bem como os sujeitos que produzem ou que são objetos de exclusão (RIBEIRO, 2006, p. 158).

Segundo a autora, a exclusão oculta a postura autoritária de uma classe que escolhe acomodar os conflitos, atendendo aos seus próprios interesses e sobrepondo-os ao bem comum, "porque náo pretende atravessar a superfície do fenômeno para ir ao fundo, ou à sua essência” (RIBEIRO, 2006, p. 158-159). $\mathrm{O}$ aprofundamento sobre a exclusão torna-se necessário em razão de permitir perceber as condiçôes materiais de vida da maior parte dos brasileiros numa perspectiva diversa da assistencialista e da de manutençáo do status quo, direcionando o pensar sobre a exclusão social para a inclusão, para a possibilidade de "re-ingresso à condição de excluído" (RIBEIRO, 2006, p. 158-159).

Nessa visão, Gentili (2009) assevera que os processos de exclusão produzidos com base no modo de produção capitalista interferem brutalmente no direito à educação no Brasil. Tal processo ocorre especialmente por meio das dinâmicas da pobreza e da desigualdade estruturais, da segmentação e da diferenciação dos sistemas nacionais de educação e dos sentidos que assume o direito à educação em um país onde a tradição 
política despreza os direitos humanos e reduz a escolarização aos valores do mercado (GENTILI, 2009, p. 1059). O autor ainda esclarece que é fundamental reconhecer que

[a] exclusão é uma relação social, e não um estado ou posição ocupada na estrutura institucional de uma determinada sociedade. Dessa forma, os que estão excluídos do direito à educação não estáo excluídos somente por permanecerem fora da escola, mas também por formarem parte de um conjunto de relaçóes e circunstâncias que os afastam desse direito, negando ou atribuindo-lhes esse direito de forma restrita, condicionada ou subalternizada (GENTILI, 2009, p. 1062).

Ao longo da história da educação brasileira, os pobres tiveram seu direito à educação negado, por meio do não acesso à escola. A questão que nos está imposta atualmente nos remete a perguntas relativas à permanência e ao sucesso escolar e ao acesso à educação de qualidade. Porém a qualidade, nesses termos, deve ser compreendida como conceito histórico vinculado às exigências sociais de cada tempo e lugar. Nesse aspecto, apesar dos avanços relacionados ao acesso à educação, um longo caminho ainda há de ser percorrido para que,no Brasil, o direito à educaçáo seja, de fato,consagrado.

\section{O PNE e o PRONATEC: as políticas públicas e o direito à educação}

As políticas públicas, em sentido mais amplo, visam assegurar direitos, corrigir desigualdades e promover o bem comum na sociedade como um todo. Portanto, elas são responsabilidade do Estado, que,para tanto,deve desenvolver uma série de açóes nas diversas áreas de interesses plurais da sociedade, fitando o seu bem comum.Nesse sentido, as políticas públicas podem ser compreendidas como o conjunto de iniciativas, açóes, planos, programas, metas e estratégias traçados pelo Estado visando ao bem-estar da coletividade e ao interesse público.

Segundo Rua (s.d., p. 1), “a política consiste no conjunto de procedimentos formais e informais que expressam relaçóes de poder e que se destinam à resolução pacífica dos conflitos quanto a bens públicos”. As políticas públicas seriam resultante das atividades políticas, compreendendo "o conjunto das decisóes e ações relativas à alocação imperativa de valores" (RUA, s.d., p. 1).Em razão da pluralidade da sociedade e, consequentemente, dos interesses em conflito, há distinção e divergências entre o que desejam os diversos grupos e atores sociais. Como os recursos destinados às políticas são limitados, ocorrem disputas pelos bens e serviços públicos.

Nesse contexto, o PNE surgiu como possibilidade de estruturação do direito à educação, trazendo luz à complexidade do modelo federativo da educação brasileira. Com a proposta de planejar a educação do país por uma década, o plano tem o compromisso de estruturar suas açóes em prol da eliminaçáo das históricas desigualdades educacionais no Brasil. 
Com a Emenda Constitucional no 59, o PNE tornou-se ponto fulcral para a elaboração dos planos estaduais, municipais e distrital de educação, uma vez que passou a ser o ponto de convergência de um sistema nacional de educação. Assim, aborda de forma incisiva a questão da definição das responsabilidades em diversos níveis — da União, do Distrito Federal, dos estados e dos municípios —, conforme determina a Constituição Federal de 1988, preconizando a composição de formas orgânicas de colaboração entre os sistemas de ensino (MEC, 2014, p. 5-6).

A origem do PNE remete-se às concepçóes e proposiçóes da Conferência Nacional de Educação (CONAE) de 2010, cujo objetivo foi a construção de um plano nacional de educação que se conformasse como política de Estado. Assim, a educação foi amplamente discutida, tanto nas conferências municipais, estaduais e distrital como na nacional. As açóes de 2009 e 2010 envolvendo instituiçôes educacionais, estudantes e seus responsáveis, representantes dos trabalhadores, representantes dos sindicatos patronais, comunidade científica e governos federal, estadual, municipal e distrital trouxeram pluralidade às discussões e proposiçóes. Por isso, o documento final da CONAE é resultado de um rico processo de debates e de construção coletiva.

Conforme Lima (2014, p. 1069), a gestão democrática "é uma complexa categoria político-educativa, uma construção social que não dispensa a análise dos contextos históricos, dos projetos políticos e da correlação de forças em que ocorre”. A participação na decisão, nessa perspectiva, emerge trazendo sentido às práticas e rompendo com os rituais formais que geralmente excluem os beneficiários de sua formulação.

Consideramos, portanto, que o PNE, apesar de seus limites, manteve o caráter democrático das conferências de educação e representa o esforço de sintetizar propostas que visam interromper a continuidade das disparidades sociais estruturais do Brasil. O plano estabelece metas estruturadas para enfrentar os impedimentos à concretização do direito à educação — acesso, permanência e sucesso escolar —, respeitando as particularidades e especificidades das populaçóes, tendo em vista a formação para o mundo do trabalho e para o exercício da cidadania.

A Lei no 13.005/2014 aprovou o PNE, tendo como principais diretrizes: a erradicação do analfabetismo e a superação das desigualdades educacionais; a universalização do atendimento escolar; a melhoria da qualidade da educação; a formação para o trabalho e para a cidadania; o princípio da gestão democrática da educação pública; a promoção humanística, científica, cultural e tecnológica do país e dos princípios do respeito aos direitos humanos; o estabelecimento de meta de aplicação de recursos públicos em educação como proporção do produto interno bruto (PIB); e a valorização dos profissionais da educação (BRASIL, 2014).

Com o intuito de cumprir seus objetivos, no PNE foram estabelecidas 20 metas e 252 estratégias específicas para o alcance de cada uma delas. Nossa análise 
tem como foco as duas metas que se relacionam diretamente com a EPT: a meta 10, cujo propósito é "oferecer, no mínimo, 25\% (vinte e cinco por cento) das matrículas de educaçáo de jovens e adultos, nos ensinos fundamental e médio, na forma integrada à educação profissional"; e a meta 11, que intenciona "triplicar as matrículas da educaçáo profissional técnica de nível médio, assegurando a qualidade da oferta e pelo menos 50\% (cinquenta por cento) da expansão no segmento público” (BRASIL, 2014).

No Brasil, a EPT, historicamente demarcada pela divisão social do trabalho, apresenta uma prática dualista em seus processos formativos. Enquanto uma rede forma o grupo privilegiado da sociedade, a outra forma os trabalhadores. Tal prática tem origem na separação entre propriedade dos meios de produção e propriedade do trabalho, ou seja, a lógica de que alguns pensam e planejam enquanto outros executam a divisão entre trabalho intelectual e trabalho manual. Por isso, as metas estabelecidas no plano propóem superar tal dicotomia, promovendo a articulação e a integração entre educação básica e EPT, buscando a elevação da escolaridade e a preparação para o trabalho. As duas metas são desafiadoras e exigem estratégias arrojadas e bem estruturadas para que a dicotomia trabalho-escola possa ser superada.

A meta 10 visa sanar a dívida histórica do país com um número expressivo de brasileiros. Muitos são os cidadãos que não tiveram acesso à educação escolar na idade certa e que se mantêm num ciclo de exclusão social (CASSIOLATO; GARCIA, 2014, p. 16).

Levando em conta essa perspectiva, a oferta da Educação de Jovens e Adultos (EJA) integrada à EPT constitui um grande desafio, especialmente quando analisamos as muitas necessidades que estáo na base das estratégias, como a adequação dos currículos aos sujeitos da EJA - tendo em vista suas faixas etárias - , a melhoria da formação dos profissionais da educação, o desenvolvimento e a utilização de metodologias e materiais didáticos apropriados, bem como o investimento na infraestrutura escolar necessária.

As estratégias da meta 10 buscam a viabilização desta, com a intenção de colocar em curso a política pública para elevação da escolaridade e formação para o trabalho. Nesse sentido, será feito o monitoramento do indicador percentual de matrículas na EJA integrada à EPT (BRASIL, 2015, p. 178).

Segundo dados do INEP, no Brasil, em 2013, foram efetuadas 103.008 matrículas na EJA integrada à EPT. A variação de 2008 para 2013 foi de 2,4\%. Cerca de quase $90 \%$ dessas matrículas ocorreram em escolas na zona urbana. Outro aspecto a ser ressaltado é que o maior crescimento do número de matrículas, durante o período supracitado, ocorreu na Região Nordeste (3,9\%), seguida das regiōes Norte (2,5\%), Centro-Oeste $(1,5 \%)$, Sudeste $(1,1 \%)$ e Sul $(0,5 \%)$. Todos esses dados demonstram a necessidade real de ampliação da escala da oferta da EJA para o cumprimento da meta prevista no PNE (BRASIL, 2015, p. 180).

No que tange à dependência administrativa, observa-se que, em 2008, a rede federal era responsável por 39,6\% das matrículas na modalidade, seguida 
das redes estadual $(29,8 \%)$, privada $(22,8 \%)$ e municipal $(8,8 \%)$. Em 2013, as redes federal e privada reduziram significativamente suas matrículas na EJA integrada à EPT, 12,6\% e 6,5\%, respectivamente, enquanto as redes estadual (44,6\%) e municipal $(36,3 \%)$ ampliaram o número de matrículas na modalidade, com $44,6 \%$ e $36,3 \%$, nessa ordem. No mesmo período, verificou-se ampliação das matrículas de mulheres, que em 2013 representavam 60,9\%,e da população com idade entre 18 e 30 anos, que nesse mesmo ano representava $72,5 \%$, bem como de negros e pardos, com 47,3\%do total de matrículas (BRASIL, 2015, p. 181-184).

Em 2013, as matrículas da EJA integrada à EPT eram 2,8\% do total de matrículas dessa modalidade. O desafio para o cumprimento da meta 10é grande, especialmente considerando os desafios para a realização das duas modalidades e da ação formativa integrada (BRASIL, 2015, p. 185).

A meta 11 propóe "triplicar as matrículas da educaçáo profissional técnica de nível médio, assegurando a qualidade da oferta e pelo menos 50\% (cinquenta por cento) da expansão no segmento público" (BRASIL, 2014). Para tanto, foram estabelecidas estratégias que remetem à expansão das matrículas de EPTNM na rede federal, ao fomento e à expansão da oferta pela rede estadual, na modalidade a distância, ao estágio curricular, aos programas de reconhecimento de saberes para fins de certificação, bem como à expansão dessa oferta nas entidades privadas de formação profissional vinculadas ao sistema sindical, à institucionalização de sistema de avaliação da qualidade da educação profissional técnica de nível médio das redes escolares públicas e privadas e à expansão do atendimento às diversas populaçóes historicamente excluídas dos processos educacionais no Brasil (BRASIL, 2014).

Tanto a meta 11 quanto as suas estratégias evidenciam a preocupação com a formação para o trabalho, sem deixar de lado a elevação da escolaridade, que permite aos egressos um horizonte de inserçáo social para além do mercado de trabalho. Os desafios impostos por essa meta podem ser sintetizados em dois grupos: a formação adequada dos profissionais da educação para atuação na EPTNM, principalmente elaborando currículos, preparando materiais didáticos e utilizando metodologias adequadas, e a adequação da infraestrutura escolar para atendimentos às demandas da modalidade, como oficinas, bibliotecas, laboratórios, salas de aula etc.

Dois indicadores foram estabelecidos para o monitoramento da meta 11: matrículas em EPTNM; e matrículas em EPTNM na rede pública (BRASIL, 2015, p. 188). Segundo o INEP, em 2013, no Brasil, foram realizadas 1.602.946 matrículas na EPTNM, porém seriam necessárias 4,8 milhóes de matrículas para que a meta fosse alcançada. No período de 2008 a 2013, houve relativo crescimento do número de matrículas nessa modalidade em todas as regiōes do país, com destaque para as regiōes Centro-Oeste (aumento de 114,9\%) e Norte (aumento de 100,2\%). 
Apesar do crescimento do número de matrículas nas regióes supracitadas, em 2013, suas maiores concentraçōes mantiveram-se nas regióes Sudeste (31,3\%) e Nordeste (30,3\%). Durante o período de 2008 a 2013,quase não se viu mudança quanto à localização das escolas que fizeram as matrículas: $95 \%$ das unidades estão em zonas urbanas (BRASIL, 2015, p. 192).

Quanto à dependência administrativa, analisando os resultados de 2013, observamos que as redes privada e estadual são responsáveis pela maior parte das matrículas na EPTNM, com 44,8 e 38,3\%, respectivamente, seguidas das redes federal (15,15\%) e municipal (92,3\%) (BRASIL, 2015, p. 193).

Considerando que os indicadores estabelecidos preconizam a quantificação do número absoluto de EPTNM e o número absoluto de EPTNM na rede pública, será analisado o quadro de cada uma das redes, comparando os dados de 2008 e os de 2013. A rede federal saiu de pouco mais de 124 mil matrículas, em 2008, para mais de $241 \mathrm{mil}$, em 2013. Enquanto isso, a rede privada, maior ofertante dessa modalidade, passou de mais de 463 mil matrículas, em 2008, para mais de 702 mil, em 2013. A rede municipal reduziu sua oferta quase pela metade: demais de 60 mil matrículas, em 2008, para pouco mais de 37 mil, em 2013. A rede estadual também cresceu, saindo das mais de 481 mil matrículas, em 2008, para pouco mais de $621 \mathrm{mil}$, em 2013. A maior concentração de matrículas em 2013 era de pessoas com idade entre 31 e 50 anos (BRASIL, 2015, p. 191-194).

A maior parte das matrículas em 2013 era de mulheres (56,7\%), e 71\% dos matriculados tinham idade entre 15 e 24 anos. No mesmo ano, $28,5 \%$ dos alunos matriculados na modalidade declararam-se brancos, $27,4 \%$ negros e $43,3 \%$ não declararam sua cor (BRASIL, 2015).

Para alcance da meta, o grande desafio refere-se ao aumento de 50\% das matrículas na rede pública, o que significa que, em números absolutos, devemos chegar em 2024 com mais de 2,5 milhōes de matrículas feitas pela via estatal. Em 2008, essa rede foi responsável por 666.161 matrículas, que representaram 59\% do total de matrículas realizadas no ano. Em 2013, a rede foi responsável por 900.519 matrículas, que representaram apenas 56,2\% do total na modalidade (BRASIL, 2015, p. 197).

A Região Sudeste concentra o maior número de matrículas $(39,9 \%)$, seguida das regióes Sul (39,3\%) e Nordeste (30\%). Quando analisamos as matrículas ofertadas pelo poder público, verificamos que a Região Nordeste possui $75,5 \%$ de suas matrículas totais na rede pública, e a Regiáo Sudeste $44,7 \%$ delas também por via estatal (BRASIL, 2015, p. 198).

Os desafios para o alcance das metas são grandes, e, para melhor acompanhamento das ações e das intervençóes, "a cada 2 (dois) anos, ao longo do período de vigência deste PNE, o Instituto Nacional de Estudos e Pesquisas Educacionais Anísio Teixeira - INEP publicará estudos para aferir a evolução no cumprimento das metas estabelecidas" (BRASIL, 2014). 
“A União promoverá a realização de pelo menos 2 (duas) conferências nacionais de educação até o final do decênio, precedidas de conferências distrital, municipais e estaduais, articuladas e coordenadas pelo Fórum Nacional de Educação"(BRASIL, 2014). Esse fórum acompanhará as açôes relativas ao PNE, bem como o cumprimento de suas metas. Além disso, promoverá a articulação entre as conferências que serão promovidas antes das conferências nacionais. Vale ainda esclarecer, quanto ao financiamento, que a meta do investimento público em educação será avaliada no quarto ano de vigência do PNE (BRASIL, 2014).

Diferentemente do PNE, que surgiu da CONAE, o PRONATEC apareceu como política de governo implantada em 2011 que fomentou a destinação de recursos públicos às entidades privadas. Nesse sentido, passaremos a tencionar algumas questóes relativas ao PRONATEC, afim de estabelecer elementos de comparação com o PNE.

A Lei $\mathrm{n}^{\circ} 12.513 / 2011^{1}$, que institui o programa, altera diversas leis anteriores a sua adoçáo, dando ao PRONATEC maior abrangência e diversas frentes de atuação. São objetivos do programa estabelecidos na lei:

I - expandir, interiorizar e democratizar a oferta de cursos de educação profissional técnica de nível médio presencial e a distância e de cursos e programas de formação inicial e continuada ou qualificação profissional; II -fomentar e apoiar a expansão da rede física de atendimento da educaçáo profissional e tecnológica; III - contribuir para a melhoria da qualidade do ensino médio público, por meio da articulação com a educação profissional; IV -ampliar as oportunidades educacionais dos trabalhadores, por meio do incremento da formação e qualificação profissional; $\mathrm{V}$ - estimular a difusão de recursos pedagógicos para apoiar a oferta de cursos de educação profissional e tecnológica; VI - estimular a articulação entre a política de educação profissional e tecnológica e as políticas de geração de trabalho, emprego e renda (BRASIL, 2011).

Para cumprir os objetivos previstos no programa, várias iniciativas foram incorporadas a ele:

1. A expansão da Rede Federal de Educação, Ciência e Tecnologia, que visa à implantação dos institutos federais no país;

2. O Programa Brasil Profissionalizado, que objetiva a ampliação da oferta e o fortalecimento da educação profissional integrada ao ensino médio nas redes estaduais;

3. A Rede e-Tec Brasil, com vistas à oferta de cursos de EPTNM e FIC na modalidade a distância; 
4. O Acordo de Gratuidade com os Serviços Nacionais de Aprendizagem (SNAs), que determina a destinação de $66,7 \%$ dos recursos da receita líquida oriunda da contribuição compulsória dos SNAs para cursos/ programas de gratuidade;

5. Bolsa Formação (estudante e trabalhador), cujos propósitos são qualificar e habilitar estudantes e trabalhadores, conforme públicos-alvo do programa.

Do ponto de vista da gestão democrática, o PRONATEC representou um retrocesso em relação à última política de qualificação em âmbito nacional: o Plano Nacional de Qualificação (PNQ), do governo Lula. O processo de gestão e organização do PRONATEC centralizou os processos decisórios no governo federal, relegando aos estados, aos municípios e ao Distrito Federal funções menores, muitas das vezes restritas à mobilização do público-alvo.

No tocante à sua origem, o programa surgiu sem a inserção da sociedade nos processos de discussão, elaboração e execução, diferenciando-se do PNQ, que incluía os entes federados no processo de execução, e distanciando-se grandemente do PNE, que emergiu da CONAE após ampla discussão nacional. O programa, embora seus objetivos o apresentem como política pública que se propunha a tratar da questão da exclusão social, na prática tem se materializado em resultados de privatismo dos recursos públicos e de aligeiramento da formação. O programa visa suprir as demandas do mercado de trabalho, como veremos a seguir, restringindo outras possibilidades de ampliação da formação dos seus beneficiários, trazendo muito mais resultados quantitativos que qualitativos.

Em 2013, o PRONATEC passou a incluir em suas iniciativas o financiamento estudantil aos estudantes matriculados em instituiçóes de ensino superior e de EPTNM, bem como as instituiçóes privadas sem fins lucrativos. Tal processo aprofundou ainda mais a política de sustentação do setor privado, em vez de manter o processo de expansão da rede federal.

As matrículas produzidas no âmbito do PRONATEC expressam sua magnitude e justificam a discussão em torno de suas açóes. As matrículas totais do programa no período de 2011 a 2014 ultrapassaram oito milhóes, e, destas, quase seis milhóes foram para cursos de curta duração - denominados decursos de FIC - e pouco mais de dois milhóes para cursos de EPTNM.

Das mais de duas milhóes de matrículas para cursos de EPTNM, 55,7\% foram realizadas pelas redes públicas, enquanto $44,3 \%$ aconteceram pela rede privada. Quando a análise das matrículas dos cursos de FIC é feita, o resultado inverte-se: das quase seis milhóes de matrículas totais, aproximadamente $85 \%$ foram realizadas pela rede privada, enquanto $15 \%$ pela rede pública. Desse modo, tratando-se de matrículas totais, o maior ofertante de vagas em EPT no âmbito do programa é a rede privada. 
A predominância de oferta de cursos de FIC, em detrimento da oferta de cursos de maior duração, situa o programa no rol de uma política de educação profissional imediatista. Configura-se, portanto, como um tipo de oferta que está longe de dar conta da problemática central que afeta a maior parte da população brasileira: a elevação da escolaridade integrada à educação profissional e tecnológica, pública e de qualidade prevista no PNE.

Esse quadro não é novidade na EPT brasileira, uma vez que em vários momentos o governo federal, ao longo da história, buscou resolver as questóes de formação da força de trabalho brasileira de maneira aligeirada, mantendo a dualidade histórica na educação brasileira. Nesse rol de programas de educação, destacamos outros similares ao PRONATEC e de abrangência nacional, como o Programa Intensivo de Preparação de Mão de Obra Industrial (PIPMOI); o Programa Intensivo de Preparação de Mão de Obra (PIPMO); o Plano Nacional de Qualificação do Trabalhador (PLANFOR); o Plano Nacional de Qualificação (PNQ), que substituiu o PLANFOR; e o ProJovem. Esses programas mostraramse não só incapazes de enfrentar a exclusão educacional como reafirmaram a dualidade que historicamente destina uma formação mais ampla para a minoria exercer trabalho complexo (intelectual) e uma formação mais restrita para a maioria atuar no trabalho simples (manual).

Lima (2012) afirma que tais programas se configuram, por conseguinte, como políticas que acabam servindo de moeda de troca política e financeira, em que o Estado paga caro por uma EPT fragmentada e incapaz de promover formação integral e emancipadora. Nesse sentido, cria-se o que se chama de mercado da formação.

Até 2015, a maior parte da oferta de vagas do PRONATEC remetia-se à dualidade no processo formativo, ou seja, mais vagas eram destinadas à EPT desvinculadas da elevaçáo da escolaridade. A partir deste ano, houve grande queda no número de matrículas em razão da redução de recursos liberados pelo governo federal. As pactuaçôes das vagas entre demandantes (diversos ministérios) e ofertantes (várias redes de EPT) diminuíram significativamente. Prova disso é o comparativo entre o número de matrículas feitas em 2014, 3.002.056 no total, e em 2015,1.266.777, segundo publicaçóes do próprio MEC em seu sítio. A partir de 2016, o programa pareceu tomar novos rumos, podendo ter sido influenciado pelo PNE e pelo momento político e econômico brasileiro.

Nesse contexto, surgiu o PRONATEC-EJA, que se relaciona diretamente à meta 10 do $\mathrm{PNE}$, que preconiza a ampliação da oferta da EJA integrada à EPT. O PRONATEC-EJA seria uma das modalidades financiadas pelo "subprograma" denominado de Bolsa Formaçáo, que viabilizaria o reconhecimento dos saberes adquiridos pelos alunos ao longo da vida. No entanto as modificaçôes dessa nova fase do programa ainda não se materializaram em matrículas na referida modalidade. 
Outro movimento diz respeito ao financiamento, haja vista que o PRONATEC 2016 previu que parte de suas açóes passariam a ser de responsabilidade financeira do Sistema S. Nele, 25\% do valor das receitas originárias de tributação compulsória do Sistema $S$ passaria a ser incorporado às açóes do PRONATEC.

Em meio ao contexto de crise estabelecido no governo Dilma Rousseff, o programa deixou de ter a pujança dos primeiros anos de sua instituição. E, embora o presidente em exercício Michel Temer tenha sinalizado que o programa continuará a ser prioridade em seu governo, resta saber se o PRONATEC - marca do governo Dilma Rousseff — resistirá aos processos de mudanças governamentais e de disputas pelo fundo público.

Ficam ainda outras questóes: que importância o novo governo dará ao PNE? Como tratará cada uma das metas estabelecidas pelo PNE, visto que há, de sua parte, um posicionamento claro quanto à manutenção do PRONATEC?

Apesar da inegável ampliaçáo do acesso à EPT, o caráter privatista do PRONATEC, via Bolsa Formaçáo, com o objetivo de formar para o mercado, viabiliza a constituição de um grande mercado da formação (LIMA, 2012, p. 511).

Nesse sentido, o PNE,em contraponto ao PRONATEC, revela-se como política de Estado que possibilita a estruturação do direito à educação na perspectiva abordada por Gentili (2009) e Ribeiro (2006). Para esses autores, é necessário analisar profundamente, e não de maneira superficial, as questôes que dizem respeito à exclusão educacional, levando em conta a muldimensionalidade desse tema e, assim, traçar caminhos possíveis para que os brasileiros possam ter acesso a uma educação pública e de qualidade socialmente referenciada, capaz de instituir um novo horizonte que proporcionaria a inclusão educacional dos que foram social e historicamente excluídos.

\section{Considerações finais}

Neste ensaio buscamos tencionar questôes que tangenciam o PNE20142024 e o PRONATEC quanto às características de políticas públicas dessas açóes governamentais, especialmente no que diz respeito ao direito à educação.

Defendemos a educação pública e de qualidade a todos os segmentos sociais, inclusive àqueles que historicamente foram e têm sido excluídos do direito à educação em sua plenitude. Acreditamos que o PNE constitui uma possibilidade de consolidação desse direito.

Da mesma forma, cremos na socialização dos conhecimentos científicos, artísticos e filosóficos historicamente produzidos pela humanidade. Acreditamos que para a promoção do homem, todo ser humano deve ser capaz de conhecer criticamente as condiçóes em que vive, de modo a intervir e transformar a sociedade rumo à ampliação da liberdade e à colaboração entre os homens. 
Com base na análise documental, discutimos a origem, a concepção e os resultados tanto do PNE quanto do PRONATEC, com o objetivo de estabelecer a articulação de cada política com os interesses em disputa na sociedade. No tocante à origem, o PNE, apesar de seus limites, emergiu da CONAE, e o PRONATEC foi apresentado sem a participação mais ampla da sociedade. Acercada concepção, o PNE revela-se como uma política pública de Estado cujas metas e estratégias, se fossem levadas a termo, possibilitariam a estruturação do direito à educação, e o PRONATEC, por sua vez, revela seu caráter de política de governo de viés privatista. Quanto aos objetivos, o PNE ainda precisa ser implementado, mas já propóe o fortalecimento do financiamento da educação pública para a oferta de uma formação mais ampla aos educandos. Enquanto isso, o PRONATEC, em execução desde 2011, tem priorizado a destinação privada dos recursos públicos para a oferta de cursos que, em sua maioria, são de curta duração, apesar dos novos rumos sinalizados em 2016.

Consideramos ainda que tais ações não garantem a eliminação das desigualdades sociais, visto que elas transcendem os aspectos estruturais ou contingenciais da educação, alicerçando-se nos fundamentos das sociedades capitalistas de países periféricos como o Brasil.

\section{Notas}

1 Institui o Programa Nacional de Acesso ao Ensino Técnico e Emprego (Pronatec); altera as Leis $\mathrm{n}^{\circ}$ 7.998, de 11 de janeiro de 1990, que regula o Programa do Seguro-Desemprego, o Abono Salarial e institui o Fundo de Amparo ao Trabalhador (FAT), no 8.212, de 24 de julho de 1991, que dispóe sobre a organização da Seguridade Social e institui Plano de Custeio, no 10.260, de 12 de julho de 2001, que dispóe sobre o Fundo de Financiamento ao Estudante do Ensino Superior, e no 11.129, de 30 de junho de 2005, que institui o Programa Nacional de Inclusão de Jovens (ProJovem); e dá outras providências.

\section{Referências}

BOMENY, H. Os intelectuais da educação: descobrindo o Brasil. Rio de Janeiro: Zahar, 2003.

BRASIL. Instituto Nacional de Estudos e Pesquisas Educacionais Anísio Teixeira (INEP)/ Ministério da Educação (MEC). Plano Nacional de Educação PNE 2014-2024: linha de base. Brasília, 2015.

Lei $n^{\circ} 12.513$, de 26 de outubro de 2011. Institui o Programa Nacional de Acesso ao Ensino Técnico e Emprego (Pronatec). Diário Oficial da União, Brasília, 2011.

Lei no 13.005, de 25 de junho de 2014. Aprova o Plano Nacional de Educação PNE e dá outras providências. Diário Oficial da União, Brasília, 2014. 
CASSIOLATO, M.M.M.C; GARCIA, R.C. Instituto de Pesquisa Econômica Aplicada (IPEA). PRONATEC: múltiplos arranjos e açôes para ampliar o acesso à educação profissional. Rio de Janeiro, 2014.

GENTILI, P. O direito à educação e as dinâmicas de exclusão na América Latina. Educação \&Sociedade, Campinas, v. 30, n. 109, p. 1050-1079, set./dez., 2009.

LIMA, L.C. A gestão democrática das escolas: do autogoverno à ascensão de uma pós-democracia gestionária? Educaçâo \& Sociedade, Campinas, v. 35, n. 129, p. 1067-1083, out./dez., 2014.

LIMA, M. Perspectivas e riscos da educação profissional do governo Dilma: educaçáo profissional local e antecipação ao Programa Nacional de Acesso à Escola Técnica (Pronatec). In: Associação Nacional de Pós-graduação e Pesquisa em Educação, 34, 3 outubro, Natal, 2011, p. 12-27. Anais... Natal: ANPED, 2011.

Educação profissional no governo Dilma: pronatec, PNE e DCNEMs. Revista Brasileira de Política e Administração da Educação, v. 28, n. 2, p. 495-513, mai/ago. 2012.

MINISTÉRIO DA EDUCAÇÃO (MEC). Planejando a próxima década: conhecendo as 20 metas do Plano Nacional de Educação. Brasília, 2014.

RIBEIRO, M. Exclusão e educação social: conceitos em superfície e fundo. Educação \& Sociedade, Campinas, v. 27, n. 94, p. 155-178, jan./abr. 2006.

RUA, M.G. Análise de políticas públicas: conceitos básicos. s.d. Disponível em: <portal. mda.gov.br/o/1635738>. Acesso em: 04 jun. 2016.

SAVIANI, D. Trabalho e educação: fundamentos ontológicos e históricos. Revista Brasileira de Educação, Campinas, v. 12, n. 34, p. 152-180, jan./abr. 2007.

Recebido em 10 de agosto de 2016.

Aprovado em 10 de outubro de 2016. 